\title{
Prestressing low clinker structural concrete elements by ultra-high modulus carbon fibre reinforced polymer tendons
}

\author{
Tobias Dominik Lämmlein · Janis Justs • Giovanni Pietro Terrasi • \\ Pietro Lura $(\mathbb{D}$
}

Received: 15 July 2020/ Accepted: 17 January 2021 / Published online: 15 February 2021

(C) The Author(s) 2021

\begin{abstract}
The combination of low clinker highperformance concrete (LCHPC) and ultra-high modulus (UHM) carbon fibre reinforced polymer (CFRP) tendons was recently proposed for prestressed structural elements. The $70 \%$ reduction in cement content resulting in limited creep and shrinkage of the LCHPC in comparison to a conventional high-performance concrete (HPC) and the very high UHM-CFRP tendon stiffness (> $509 \mathrm{GPa}$ ) were expected to impact the mechanical behaviour of such structures. This study focuses on the behaviour of $3 \mathrm{~m}$-long beam specimens during prestressing, concrete hardening and in 4 pointbending experiments. Fibre optic sensors were implemented inside the CFRP tendons to measure strain during those stages and a digital image correlation system was employed to monitor the 4-point-bending
\end{abstract}

T. D. Lämmlein $(\varangle)$ · J. Justs · G. P. Terrasi · P. Lura Empa, Swiss Federal Laboratories for Materials Science and Technology, Überlandstrasse 129, 8600 Dübendorf, Switzerland

e-mail: Tobias.Laemmlein@empa.ch

G. P. Terrasi

e-mail: Giovanni.Terrasi@empa.ch

T. D. Lämmlein · P. Lura

Institute for Building Materials (IfB), ETH Zurich,

8092 Zurich, Switzerland

\section{G. P. Terrasi}

Institute for Infrastructure and Environment, School of Engineering, University of Edinburgh,

Edinburgh EH9 3FB, UK tests. After 28 days, the LCHPC recipe, despite a 70\% cement reduction and much smaller environmental footprint, did not show measurable differences in the prestress loss behaviour in comparison to a conventional HPC. The UHM-CFRP prestressing tendons, because of their stiffness, showed both higher prestress losses of around $40 \%$ and on average a nearly doubled prestress transfer length. However, they increased the beam's maximum load-bearing capacity by $21 \%$ and showed $47 \%$ less deflection at failure in comparison to beams prestressed with the standard modulus (UTS)-CFRP tendons.

Keywords Prestressed concrete - Low-clinker-highperformance-concrete (LCHPC) - Carbon fiber ·

Optical fiber bragg grating · Prestress-losses $\cdot$ Prestress transfer . Bending behavior

\section{Introduction}

Sustainable and innovative designs in construction can make a significant contribution for improving the carbon footprint of structures in the future. In terms of structural design, there are two main approaches to tackle this challenge. The first approach consists in reducing the environmental impact of the employed materials. The second approach is based on optimizing 
the mechanical performance at the structural level and hence the effectiveness in the use of materials.

Already in the 1990s, one first step for improving the structural design of building facades was the development of slender carbon fibre reinforced polymer (CFRP) prestressed elements [1, 2]. However, for nearly two decades, the space for further developments in this field was constricted by both the high price of the materials and by existing standards. Currently, standard modulus CFRP costs about $20 € /$ $\mathrm{kg}$. Ultra-high modulus (UHM) carbon fibre reinforced polymers have become recently more affordable with a cost of about $50 € / \mathrm{kg}$ [3]. In addition, new guidelines $[4,5]$ are allowing the development of novel low clinker high performance concretes (LCHPC) with clinker replacement levels of up to $70 \%$ [6]. The combination of both materials results in a very promising composite system that satisfies both the sustainability aspects and the technical improvement objectives.

Prestressing of concrete became technically feasible with the invention of high strength steels and was first realized by Freysssinet in the 1920s [7]. By counteracting tensile stresses in concrete, the prestressing technique allowed the manufacturing of lighter structural elements at much lower cost. Later in the 1970-1980 s, fibre reinforced polymers were first brought to use in concrete structures [8]. Due to their excellent strength, their low weight and their corrosion resistance, these materials gained international attention and were widely investigated for strengthening, retrofitting and prestressing of structures. In particular CFRP, having the highest strength and stiffness among all fibre reinforced polymers, can be seen as the technically ideal material for prestressing applications [9]. In contrast to glass-fibre and aramid-fibre reinforced polymers, CFRP is not subjected to stress corrosion [10] or creep [9, 11], respectively. Since the invention of the prestressing technique, the load deflection behaviour of a prestressed concrete structure was linked with the level of prestress and hence dependent thereon. In consequence, it was crucial for the designers and engineers to assess the amount of prestress loss over time, which needed to be considered in their designs. First investigated by Magnel [7, 12], this finally resulted in numerous codes and recommendations, e.g. [13-16]. In the case of internal prestressing by CFRP tendons ${ }^{1}$ using the pre-tensioning technique, the main contributors to prestress losses can be seen as elastic shortening, shrinkage and creep of concrete. The measurement and monitoring of prestress losses was performed by different approaches. In [17], Maaskant et al. implemented fibre-optic Bragg grating (FBG) sensors on steel and CFRP prestressing tendons to monitor the prestress losses. The losses were found to be $25 \%$ lower for CFRP tendons compared to steel tendons, mostly due to the lower stiffness of the CFRP. In a later study [18], detachable mechanical strain gauges were placed at a $50 \mathrm{~mm}$ distance on the sidewall of prismatic concrete specimens, to evaluate prestress losses without disturbing the bond between tendon and concrete. In combination with prestress force measurements and additionally performed shrinkage tests, they were able to show that shrinkage, creep and elastic shortening contribute each with significant amounts to prestress losses. Total losses ranged from $25 \%$ up to $60 \%$ over one year, dependent on specimen size and concrete recipe. Direct application of strain gauges on the surface of the tendons was also employed [19], however neglecting bond disturbance. With this technique, they were able to record a prestress development up to $600 \mathrm{MPa}$ in a selfprestressed configuration which was driven by an expanding concrete recipe. Recently, a prestressed concrete strand with an integrated FBG sensor to allow prestress measurements in concrete structures was developed [20]. The center wire of the strand was exchanged with a CFRP wire and a FBG sensor was inserted into the CFRP wire during production. They were able to measure strains up to $14,000 \mu \varepsilon$, which is larger than the typically design prestress of a conventional steel strand.

In pre-tensioned elements the prestress needs a certain distance starting from a structure's boundary to be transferred by bond to the concrete. The distance needed to reach the fully prestressed section in a prestressed concrete element is commonly referred to as the prestress transfer length. Knowing precisely where a structural component is fully prestressed and hence external loads could safely be introduced is indispensable. In [21], a pioneering work, Bruggeling outlined all major steps to describe transmission of prestress by bond. Up to that paper, no realistic model

\footnotetext{
1 Note: The prestressing elements called "tendons" in this paper, see [3, 28 37], are also commonly called "strands" in the literature".
} 
had been developed that was able to describe the context of prestress transfer as a whole, neither has this theoretical feat been accomplished since. On the other hand, numerous experimental studies investigating the prestress transfer length of FRP tendons were conducted in the last 20 years. The main outcome in [22], a study of the transmission mechanism of prestress to concrete by FRP, was that the transfer length is mainly affected by the surface characteristics and the size of the tendons. Furthermore, in [22], it was shown that the mechanism of load transfer is different in FRP compared to classic steel tendons. In this study, FRP's transfer was seen related to adhesion and mechanical interlock, while steel tendons were subjected to transfer by mostly friction. A study about the force transfer of FRP bars in concrete [23] showed that a sand-coated FRP bar had a stress transmission length limited to only $16 \varnothing$ and proved that this length was smaller in comparison to steel tendons.

The tensile behaviour of CFRP is linearly elastic until failure, in contrast to the elastic-plastic response of steel. It is therefore to be expected that the brittleness of the CFRP will affect the structural behaviour of a prestressed concrete structure. The structural behaviour of precast prestressed beams, façade elements and slabs requires further investigation and the development of new guidelines. Several institutions around the world were involved in this process for FRP materials since the 1980s. Their findings and approaches have first been reviewed in [24] and more comprehensively in [25]. Both reviews commented that the used FRPs had a lower elastic modulus in comparison to steel and hence they would increase the deflection and the crack width in loaded concrete structures. Additionally, in a study about the rational use of advanced composites in concrete, it was stated that the structural use of FRPs is generally feasible [26]. Later, Bakis concluded that FRP applications would probably be restricted to cases where their properties of low weight, high strength or corrosion resistance are crucial [25].

The short-term and long-term flexural behaviour of FRP prestressed concrete elements were studied experimentally and modelled analytically [1, 27-32]. Recently, Rezazadeh et al. proposed a new simplified approach to predict the flexural behaviour of CFRPprestressed, simply-supported beams [33]. This model was developed in the scope of flexural strengthening with externally bonded and prestressed strips. The new method, based on strain compatibility and on the principle of static equilibrium, showed a good predictive performance for the load deflection behaviour. All of the discussed studies used CFRP tendons with longitudinal stiffness's lower than $200 \mathrm{GPa}$ [27-30, 33, 34]. The new UHM-CFRP tendons considered in this study are substantially stiffer than classic CFRP materials and even stiffer than steel. In this context standard modulus carbon fibres are typically referred to have a stiffness in the range of 220-240 GPa and carbon fibres with UHM properties a stiffness of more than $520 \mathrm{GPa}$ [35]. Their corresponding ultimate tensile strength lies in the range from 2050 to $3790 \mathrm{MPa}$ for standard modulus and 1380-2400 MPa for UHM-CFRP fibres. However, the latest developments of UHM-fibres are even exceeding this strength. It could be anticipated that this difference in stiffness will have significant influences on the structural behaviour. It must also be remarked that the reduced clinker content in the novel LCHPCs would cause faster carbonation and hence would be a limitation for the use of classic prestressing steel. The proposed UHM-CFRP tendons, not unlike other CFRP materials, are practically immune to corrosion and hence ideal for the proposed implementation in LCHPCs.

The goal of this work was to provide a first structural characterization of LCHPC beams prestressed with UHM-CFRP prestressing tendons. To support the design of efficient and sustainable structures, the effects of the new LCHPCs and of the UHM CFRP tendons on the prestress behaviour were of particular interest. This study identifies the amounts of each individual contributor to the total prestress loss, precisely measures the prestress transfer length of the CFRP tendons and discusses approaches for improving the ultimate load bearing capacity of CFRPprestressed beam elements.

\section{Materials and methods}

New materials for prestressing of structural concrete elements, UHM-CFRP and LCHPCs introduced in 2016 [3] and 2019 [6] respectively, were tested to observe their behaviour during prestressing and during 4-point bending tests of such elements. In addition, the structural behaviour of these beams was further characterized. The related materials, their 
characterization methods and the experimental program are described in this section.

\subsection{Raw materials and composites}

A high performance self-compacting concrete (HPSCC) was selected to investigate the influence of the CFRP prestressing tendon's stiffness on the structural performance of prestressed concrete beams. This concrete recipe with a water to binder ratio $(\mathrm{w} / \mathrm{b})$ of 0.35 , named $\mathrm{C} 1$, contained $443.0 \mathrm{~kg} / \mathrm{m}^{3}$ of ordinary Portland cement CEM I $52.5 \mathrm{R}, 120.0 \mathrm{~kg} / \mathrm{m}^{3}$ fly ash, $20.0 \mathrm{~kg} / \mathrm{m}^{3}$ silica fume, $1107 \mathrm{~kg} / \mathrm{m}^{3}$ sand $0 / 4,487 \mathrm{~kg} /$ $\mathrm{m}^{3}$ gravel $4 / 8$ and $5.2 \mathrm{~kg} / \mathrm{m}^{3}$ superplasticizer (SP). This is the same recipe that was recently employed as a reference mix during the development of LCHPCs [6], based on a HPC used by the Swiss precast industry in CFRP prestressed structural elements [36]. In addition, to evaluate the potential of LCHPCs for prestressing applications, the recipe $\mathrm{C} 4(\mathrm{w} / \mathrm{b}=0.17)$ was chosen from three recently developed LCHPCs [6]. In this recipe (now containing only $134.3 \mathrm{~kg} / \mathrm{m}^{3}$ of cement), large amounts of cement were substituted with $511.7 \mathrm{~kg} / \mathrm{m}^{3}$ limestone filler. Further, the amount of silica fume was increased to $67.2 \mathrm{~kg} / \mathrm{m}^{3}$. The amount of sand and gravel was the same as in $\mathrm{C} 1$. The clinker reduction between $\mathrm{C} 4$ and $\mathrm{C} 1$ was $70 \%$; both mixtures were presented in detail recently [6].

All concrete compositions were mixed in a 250-1 Eirich RV11 mixer. For the recipe C1, all dry components were tumbled for $60 \mathrm{~s}$, afterwards water was added and finally the concrete was mixed for $120 \mathrm{~s}$ until a uniform mixture with good flow properties was achieved. The LCHPC mixture C4 was mixed in a slightly adapted manner. Tumbling of the dry components was performed but with a reduced amount of only $100 \mathrm{~kg}$ sand $0 / 4$. Then water was added and the recipe was mixed until the superplasticizer started functioning. Finally the remaining aggregates of sand $0 / 4$ and gravel $4 / 8$ were added and the recipe was mixed for another $120 \mathrm{~s}$ until a uniform mass with good flow properties was achieved.

Air void content and density, were measured according to EN 12350 (2009) directly after mixing, see Table 1. Concrete flow was measured in [6] with $72.5 \mathrm{~cm}$ for the $\mathrm{C} 1$ recipe and $57.5 \mathrm{~cm}$ for the $\mathrm{C} 4$ recipe. Subsequently after mixing a total of nine $150 \times 150 \times 150 \mathrm{~mm}^{3}$ cube specimens and five beam specimens were cast from one mix for each concrete/CFRP combination.

The compressive strength of the concretes was tested on three $150 \times 150 \times 150 \mathrm{~mm}^{3}$ cubes after 3 and 28 days, following standard EN 12390 (2009). In addition, the static E-modulus of the concretes was measured after 28 days on cylinder specimens $(\mathrm{d}=50 \mathrm{~mm}, \mathrm{~h}=150 \mathrm{~mm})$, following the standard EN 12390 (2013) Method B. Until testing, the samples were stored in a climatic room at $20{ }^{\circ} \mathrm{C} \pm 0.3{ }^{\circ} \mathrm{C}$ and $\mathrm{RH}>95 \%$. The storage conditions of the beam specimens are specified in the general part of Sect. 2.2. The static E-modulus of LCHPC $\mathrm{C} 4$ was $41.7 \pm 0.2 \mathrm{GPa}$ and the one of the HPC $\mathrm{C} 1$ was $35.1 \pm 0.8 \mathrm{GPa}$. Further test results of all investigated concretes can be found in Table 1. Shrinkage and creep tests on the respective concretes were not performed separately during this study. Those results were gained previously in [6] generally following SIA 262 at $20{ }^{\circ} \mathrm{C} \pm 0.3{ }^{\circ} \mathrm{C}$ and at $70 \% \mathrm{RH} \pm 3 \%$ RH. In [6], after 28 days, shrinkage was measured at $-0.38 \%$ for the HPC $\mathrm{C} 1$ and $-0.17 \%$ for the LCHPC C4; the 28 day creep measurements showed $-0.61 \%$ and $-0.41 \%$ respectively. In contrast to SIA 262, the creep samples were loaded in a sequence of increasing compressive stress applied at 3, 7 and 28 days after casting; at each loading step, the total stress was changed and corresponded to $20 \%$ of the respective compressive strength at this time point. Details can be found in [6].

In this study, two significantly different CFRPtendon materials were investigated both with a fiber volume content of $60 \%$. The first tendon type was a standard-modulus CFRP material (UTS-CFRP) and consisted of Tenax ${ }^{\circledR}$-J/E-UTS50 carbon fibres (Teijin Carbon Europe GmbH, Germany) in combination with a Huntsman XB3515/AD5021 hot-melt epoxy system. The second tendon type was made out of Mitsubishi DIALEDTM K13916 ultra high modulus (UHM) carbon fibres (Mitsubishi Rayon Co. Ltd., Japan) also in combination with the Huntsman XB3515/AD5021 hot-melt epoxy system; hereafter named UHM-CFRP.

The tendon materials were characterized in tensile tests following the standard EN 2561. The longitudinal elastic modulus of the UTS-CFRP tendon was $\mathrm{E}_{11}$ of $145 \pm 3 \mathrm{GPa}$ and the one of the UHM-CFRP tendon was $\mathrm{E}_{11}$ of $509 \pm 13 \mathrm{GPa}$ [3]. The corresponding tensile strength values can be found in Table 4. Both tendon types were produced by 
Table 1 Properties of Concretes

\begin{tabular}{|c|c|c|c|c|c|c|c|c|c|c|c|c|}
\hline \multirow[t]{2}{*}{ Concrete recipe } & \multicolumn{2}{|c|}{$\begin{array}{l}\text { Compressive } \\
\text { Strength } \\
3 \text { days }\end{array}$} & \multicolumn{2}{|c|}{$\begin{array}{l}\text { Compressive } \\
\text { Strength } \\
28 \text { days }\end{array}$} & \multicolumn{2}{|c|}{$\begin{array}{l}\text { Compressive } \\
\text { E-Modulus } \\
3 \text { days }\end{array}$} & \multicolumn{2}{|c|}{$\begin{array}{l}\text { Compressive } \\
\text { E-Modulus } \\
28 \text { days }\end{array}$} & \multicolumn{2}{|c|}{$\begin{array}{l}\text { Tensile } \\
\text { Strength } \\
28 \text { days }\end{array}$} & \multirow{2}{*}{$\begin{array}{l}\text { Density } \\
\left(\mathrm{kg} / \mathrm{m}^{3}\right)\end{array}$} & \multirow{2}{*}{$\begin{array}{l}\text { Air void content } \\
(\%)\end{array}$} \\
\hline & (MPa) & SD & (GPa) & SD & $(\mathrm{GPa})$ & $\mathrm{SD}$ & $(\mathrm{GPa})$ & $\mathrm{SD}$ & (MPa) & SD & & \\
\hline C1(HPC)-reference* & 56.9 & 0.5 & 85.7 & 1.1 & 29.0 & 0.9 & 35.4 & 0.4 & 6.6 & 0.8 & 2307 & 3.6 \\
\hline C1 (HPC)-UTS-Mix & 61.8 & 0.3 & 87.5 & 1.6 & n.a & n.a & 35.2 & 0.6 & n.a & n.a & 2272 & 3.5 \\
\hline C1 (HPC)-UHM-Mix & 62.8 & 0.3 & 87.9 & 1.8 & n.a & n.a & 35.1 & 0.8 & n.a & n.a & 2274 & 3.9 \\
\hline $\begin{array}{l}\text { C4 (LCHPC)- } \\
\text { reference* }\end{array}$ & 35.1 & 0.1 & 83.3 & 1.0 & 26.8 & 0.2 & 38.8 & 0.6 & 4.7 & 0.6 & n.a & n.a \\
\hline $\begin{array}{l}\text { C4 (LCHPC)-UHM- } \\
\text { Mix }\end{array}$ & 32.9 & 0.5 & 88.3 & 1.2 & n.a & n.a & 41.7 & 0.2 & n.a & n.a & $2368^{*}$ & $3.2 *$ \\
\hline
\end{tabular}

*Data equivalent to[6]

n.a. means not available

SD means standard deviation

Air void content and density following EN 12350

Carbolink AG (Fehraltdorf, Switzerland) in a tape laying method with a cylindrical surface and a diameter of $\mathrm{d}=5.3 \mathrm{~mm}$. After curing, the tendons were coated with quartz sand particles $(63-500 \mu \mathrm{m})$ to enhance the bond between the tendons and the concrete. The chosen sand coating showed its effectiveness recently not only due to its strong bond to concrete but also due to its bond durability [28, 37]. The sand-coated UHM-CFRP tendon was the same tendon type as previously used in $[3,36]$ but produced in another batch.

\subsection{Prestressed concrete beam elements}

To evaluate the structural behaviour of UHM-CFRP prestressed LCHPC elements, a slender beam geometry was chosen. The beam length was set to $3000 \mathrm{~mm}$, with a height of $\mathrm{h}=157.5 \mathrm{~mm}$ and a width of $\mathrm{w}=90 \mathrm{~mm}$, see Fig. 1. This geometry followed, albeit scaled down to $3 / 4$, an earlier work in the field of "Pretensioned prestressed concrete members" by Nanni and Tanigaki [38]. The prestressing tendons were positioned at a distance of $22.5 \mathrm{~mm}$ to the bottom and the sidewalls of the beam respectively. The resulting low concrete cover and the chosen prestress level of $800 \mathrm{MPa}$ inside the CFRP prestressing tendons were based on recent literature [39]. In contrast to practical prestressed concrete design, in this study, the prestress level of $800 \mathrm{MPa}$ was not

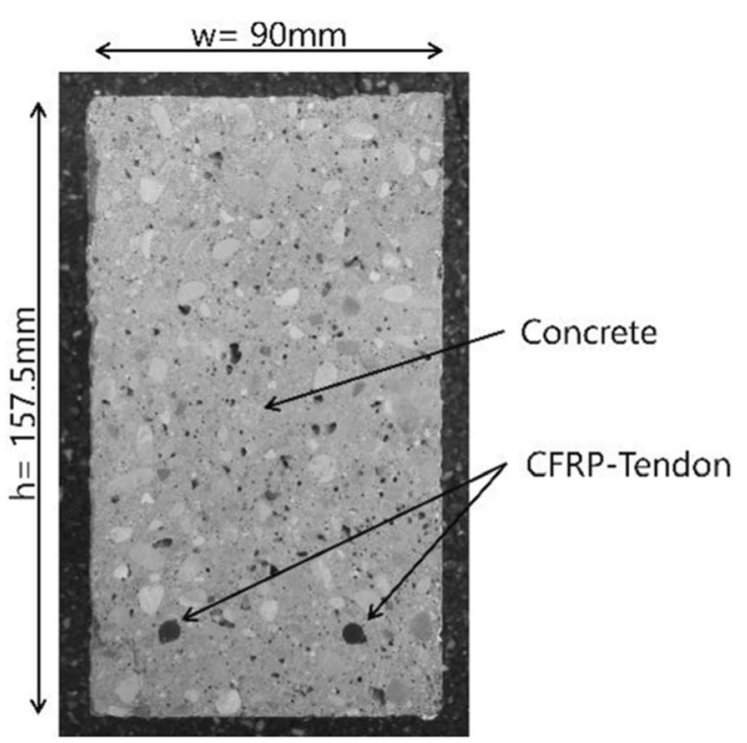

Fig. 1 Cross section of CFRP-prestressed concrete beam

adapted according to the different CFRP or concrete material properties. Having the same initial prestress enabled a clear and easy comparison between all investigated material configurations.

The beam elements were produced at Empa by the aid of a specially-designed prestressing rig. This rig allowed the production of up to five beam specimens and the application of the prestressing force to all employed prestressing tendons at once by using two 
hydraulic cylinders. In addition, to reach a consistent prestress level of $800 \mathrm{MPa} \pm 5 \%$, each tendon could be adjusted individually by a thread mechanism. The initial prestress level was monitored for each tendon by the aid of a strain gauge which was applied in the free length of the tendon between the formwork and the tendon clamping mechanism. The prestress was released three days after casting. Afterwards the samples were stored in a climate chamber at $20{ }^{\circ} \mathrm{C} \pm 0.3{ }^{\circ} \mathrm{C}$ and $90 \% \pm 3 \%$ RH until 21 days after production. Then the beams were transported into the mechanical testing laboratory and stored until 28 days after casting in controlled climate conditions of $23{ }^{\circ} \mathrm{C} \pm 2{ }^{\circ} \mathrm{C}$ and $50 \% \pm 5 \% \mathrm{RH}$.

In total, 15 concrete beam elements were cast, 5 beams each for the following combinations; UHMCFRP and C1, UTS-CFRP and C1, UHM-CFRP and $\mathrm{C} 4$. All three sets consisting of 5 beams were produced from one single batch of concrete.

\subsection{Optical fibre strain measurements}

The tape-laying production method of the CFRP tendons allowed for the implementation of fibre optic sensors in the centre of the CFRP prestressing tendon along the tendon's longitudinal axis. The very thin fibre optic sensor $(\mathrm{d}=125 \mu \mathrm{m})$ had no significant influence on the diameter of the CFRP prestressing tendon but allowed strain measurements inside the tendon without affecting the tendon's sand-coated surface. Each sensing point inside the fibre optic sensor was represented by a $5 \mathrm{~mm}$-long fibre Bragg grating (FBG). A FBG is in principle a periodic microstructure with a varying refractive index which can be written into the core of the optical fibre by intense ultraviolet light. When strained, the FBG elongates, the fibre index changes and hence the reflected Bragg wavelength of the FBG shifts. The measurement of this shift can be analysed and correspondingly the strain at the position of the FBG can be calculated [40]. A detailed summary of the FBG measurement principle, their possible applications and variations can be found in [41].

The fibre optic sensors used in this work were DTGA3A4-A01 fibres produced by FBGS International NV (Geel, Belgium) and supplied by Com\&Sens bvba (Eke, Belgium). To preserve the sensitive optical fibre from damage, a thin Teflon tube of $\mathrm{d}=0.9 \mathrm{~mm}$ covered the optical fibre as far as $0.32 \mathrm{~m}$ ahead of the first sensing point. In addition, to safely protect the optical fibre when outside the CFRP tendon and up to reaching the connector to the measurement device, a robust Teflon tube of $\mathrm{d}=3 \mathrm{~mm}$ was additionally employed.

The available 15 FBG sensing points in the optical fibre were positioned to be able to best record the prestress transfer length. Their detailed positions along the $3 \mathrm{~m}$-long concrete beam specimen can be found in Table 2. The final positioning of the sensing points in the respective prestressed concrete beam element were determined by the aid of a reference marking, which was placed on the 3-mm protective Teflon between the end of the concrete beam and the optical fibre connector. Based on the distance measured between the reference point and the concrete beam and the condition of zero stress in the tendon outside the beam after prestress release, the exact position of the first FBG was evaluated and used as reference during the analysis. Before casting, the optical fibres were connected to an FBG SCAN 804D high precision measurement device and the reference zero strain level was set in the analysis software Illumisense V2.2.

The prestress transfer length, see Table 2, was measured based on the sensing points of Group A and the measurement of the prestress level was based on the sensing points of Group B. As proposed in literature [42], the prestress transfer length calculation was based on reaching $95 \%$ of the full prestress measured in Group B. The final prestress transfer length was calculated by linear interpolation between two sensing points of Group A where the $95 \%$ criterion was reached. The prestress level after casting was calculated for all time points and beam configurations in relation to the first strain measurement taken three days after casting right before the prestress release. This first measurement was considered to correspond to $100 \%$ prestress and the subsequent prestress levels were calculated based on this point.

\subsection{Digital image correlation}

A LIMESS-Q400 two-camera digital image correlation system (LIMESS Messtechnik u. Software $\mathrm{GmbH}$, Germany) was set up for monitoring the beam elements during loading. In combination with the analysis software Istra4D (Dantec Dynamics A/S, Denmark), this arrangement allowed measuring the 
Table 2 Specified FBG sensing point position along the concrete beam

\begin{tabular}{|c|c|c|c|c|c|c|c|c|c|c|c|c|c|c|c|}
\hline Sensing point \# & 1 & 2 & 3 & 4 & 5 & 6 & 7 & 8 & 9 & 10 & 11 & 12 & 13 & 14 & 15 \\
\hline Position along beam length (mm) & 0 & 12 & 24 & 36 & 60 & 84 & 108 & 156 & 204 & 300 & 996 & 1248 & 1752 & 2004 & 2760 \\
\hline Group & A & A & A & A & A & A & A & A & A & A & B & B & B & B & A \\
\hline
\end{tabular}

concrete beam's deflection and the strain distribution on the vertical face in the beam's middle third.

The two cameras, each with a $1^{\prime \prime}$ sensor and $6 \mathrm{MP}$ resolution, were mounted in a stereoscopic setup on one tripod and placed approximately $1.8 \mathrm{~m}$ in front of the experimental setup. The lenses of the cameras had a focal length of $16 \mathrm{~mm}$. The field of view (FOV) in this arrangement was about $1.5 \mathrm{~m}$ wide. The camera set up was calibrated with an AL_35_WMB_9 $\times 9$ calibration target using the implemented procedure in the analysis software Istra 4D. On the vertical surface of the concrete beams, facing the cameras, a randomly-distributed contrast pattern (speckle pattern) was applied. Pictures were taken during the 4 point bending experiments every $2 \mathrm{~s}$. The local surface pattern was automatically assigned in the camera images and the strain distribution as well as the beam's deflection could be evaluated.

\subsection{Four point bending experimental setup}

To investigate the influence of a LCHPC and a UHMCFRP prestressing tendon on the load bearing capacity of prestressed concrete beams, a simple 4-point bending test configuration was chosen. The distance between the beam support points was set to $2500 \mathrm{~mm}$. This allowed an overhang of $250 \mathrm{~mm}$ on each side of the beam and avoided interaction between the prestress transfer area and the loaded beam section. The load was applied by a servo hydraulic cylinder and transferred to the beam by means of a spreader beam. The range of constant bending moment was set to $840 \mathrm{~mm}$ in this configuration. All contact points to the concrete beam were steel cylinders with a diameter of $\mathrm{d}=50 \mathrm{~mm}$. An overview of this 4-point bending set up is shown in Fig. 2. Moreover, the mid beam deflection was measured by a linear variable differential transformer (LVDT) of type W20TK HBM (Hottinger Baldewin $\mathrm{GmbH}$ (HBM), Germany) to validate the DIC measurement. Results shown by the
LVDT and the DIC showed negligibly small differences. Hence, possible deformations of the setup, concrete crushing or small geometrical imperfections did not affect the values recorded. All beams were loaded continuously at a servo hydraulic cylinder velocity of $1 \mathrm{~mm} / \mathrm{min}$ until failure.

\section{Results}

\subsection{Prestress transfer length and loss}

The first strain measurements inside the CFRP prestressing tendons were taken three days after casting, right before and after the prestress release. The measurement was repeated for all beams at 7, 14, 21 and 28 days after casting. One additional measurement was performed for C4-UHM-CFRP beams 4 days after casting.

All five beams of type C1-UTS-CFRP were equipped with one sensing and one non-sensing CFRP tendon. One sensing CFRP tendon was damaged during transport after the 21 day measurement. In the beam configurations of type C1-UHM-CFRP and C4UHM-CFRP, four of the five beams were initially equipped with one sensing and one non-sensing CFRP tendon. In these groups of beams, the remaining beam was equipped with two non-sensing CFRP tendons. However, for the C4-UHM-CFRP beams, the very brittle material behaviour of the UHM-CFRP led to the loss of one sensor cable during demolding and the loss of another during transport after the 21 day measurement.

After 28 days, the average prestress transfer length in the beams C1-UHM-CFRP was found to be $181 \mathrm{~mm}$ with a standard error of the mean (SEM) of $\pm 28 \mathrm{~mm}$. The same behaviour was found for the beams C4-UHM-CFRP with a prestress transfer length of $148 \mathrm{~mm}$ and a SEM of $\pm 18 \mathrm{~mm}$. The beams using a standard modulus CFRP tendon, C1-UTS-CFRP 


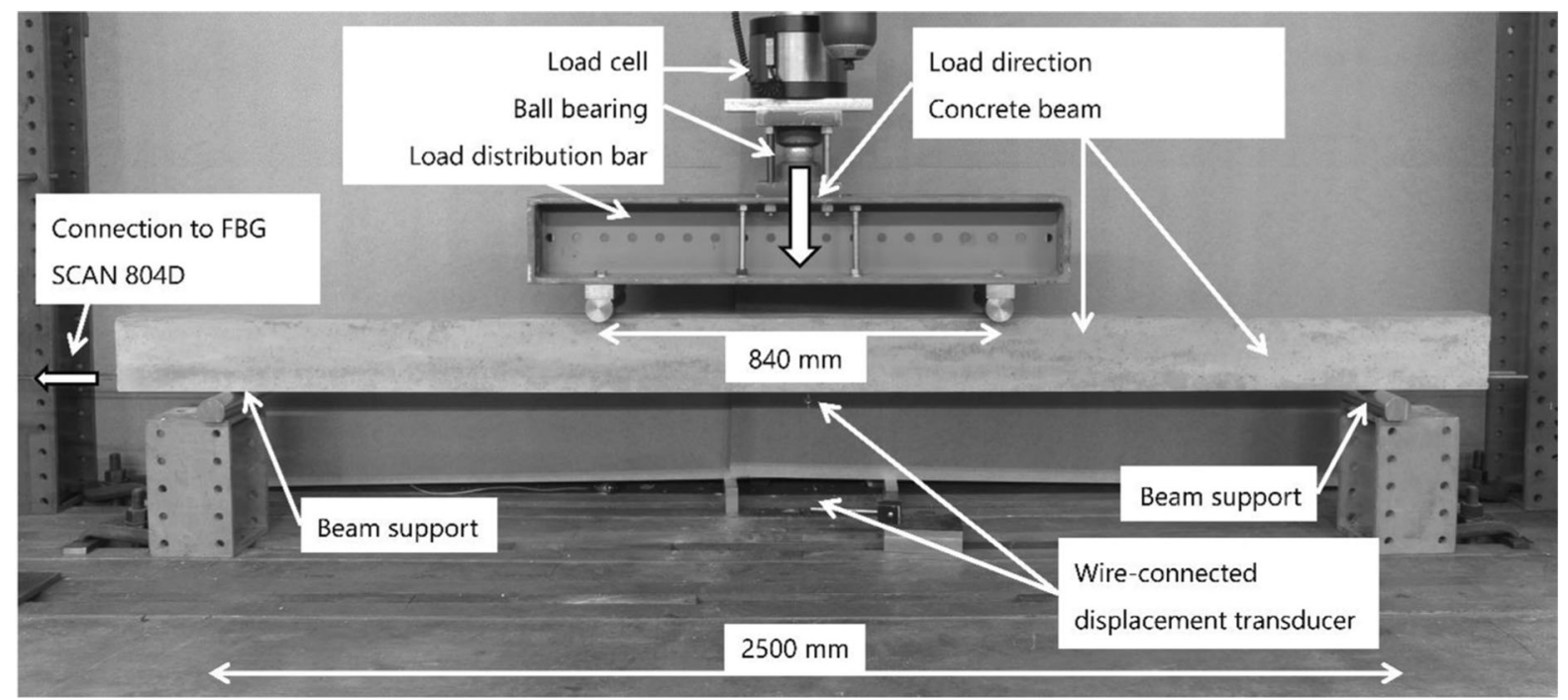

Fig. 2 Four point bending test configuration: Overview of mounted sample in experimental set-up, span $2500 \mathrm{~mm}$, load span $840 \mathrm{~mm}$ and shear span $830 \mathrm{~mm}$

showed a significantly shorter prestress transfer length of only $93 \mathrm{~mm}$ and a much smaller SEM of $\pm 4 \mathrm{~mm}$. The difference in the SEM between beams prestressed with UHM-CFRP tendons and beams prestressed with UTS-CFRP tendons can be explained by the huge difference in the tendon's longitudinal stiffness. The stiff tendons react much more sensitive to material inhomogeneities or imperfections and hence show a much larger scatter. At selected time points between prestress release and until 28 days after casting, no significant change in the prestress transfer length could be observed for any of the investigated beam types. The detailed results of the prestress transfer length measurement can be found in Fig. 3. In this Figure, the obvious drop in the prestress transfer length for C4-UHM beams after 28 days was caused by the loss of one sensing tendon. As a consequence, the last calculation of the averaged prestress transfer length for C4-UHM-CFRP beams, see Fig. 3, was based only on two beams.

The initial prestress level after release, see Fig. 4, was on average $75 \%$ for C1-UHM-CFRP beams, $96 \%$ for C1-UTS-CFRP beams and $75 \%$ for C4-UHMCFRP beams, respectively. The initial camber of the beams after the prestress release was calculated based on the remaining prestress force to be $0.75 \mathrm{~mm}$ for $\mathrm{C} 1$ UHM CFRP prestressed beams, $0.7 \mathrm{~mm}$ for C4-UHMCFRP prestressed beams and $1.32 \mathrm{~mm}$ for C1-UTSCFRP prestressed beams. Afterwards, the prestress level of all investigated beams showed a clear decrease in the first 28 days. The total loss $(42 \%$ of the initial prestress) was most pronounced in the beams C4UHM-CFRP. The C1-UHM-CFRP beams showed also a high loss of $40 \%$, while the C1-UTS-CFRP beams showed significantly smaller losses of only $11 \%$ when measured 28 days after casting. A detailed overview of the prestress level and its behavior in the first 28 days for each configuration can be found in Fig. 4. The prestress development after 28 days and the position of the prestress transfer length in the end zone of the beam is given for completeness in Fig. 5, the shown prestress development is representative for all time points between 3 and 28 days. In addition, the stresses inside the concrete after 28 days related to prestressing were calculated based on the results presented above and by using the adapted model of [33]. In the compressive zone C1-UTS-CFRP beams were compressed on average by $0.020 \%$, C4-UHMCFRP beams by $0.014 \%$ and C1-UHM-CFRP beams also by $0.014 \%$, the stresses were $5.8 \mathrm{MPa}, 3.75 \mathrm{MPa}$ and 4.06 MPa respectively.

\subsection{Concrete beam deflection and maximum load bearing capacity}

The aim of this experimental program was to investigate the influence of UHM-CFRP prestressing tendons and LCHPC on the structural behaviour of 


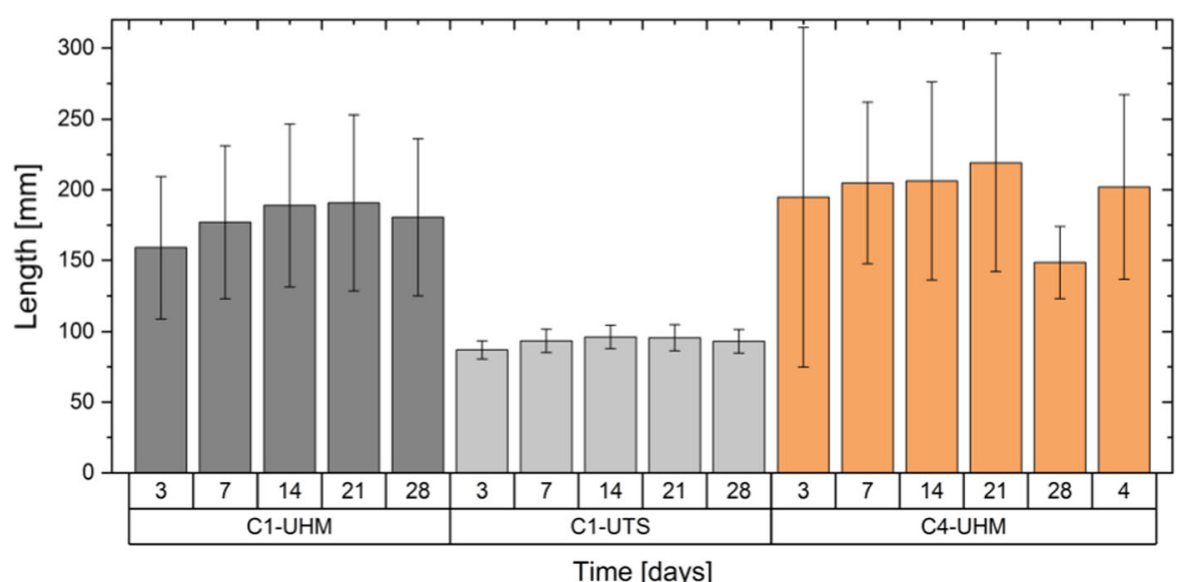

Fig. 3 Prestress transfer length development in the first 28 days after casting. The bars show the average value of the beams investigated and their standard deviations. The drop in prestress transfer length for the C4-UHM-CFRP beams after 28 days is caused by the loss of one sensing tendon after the 21 day measurement

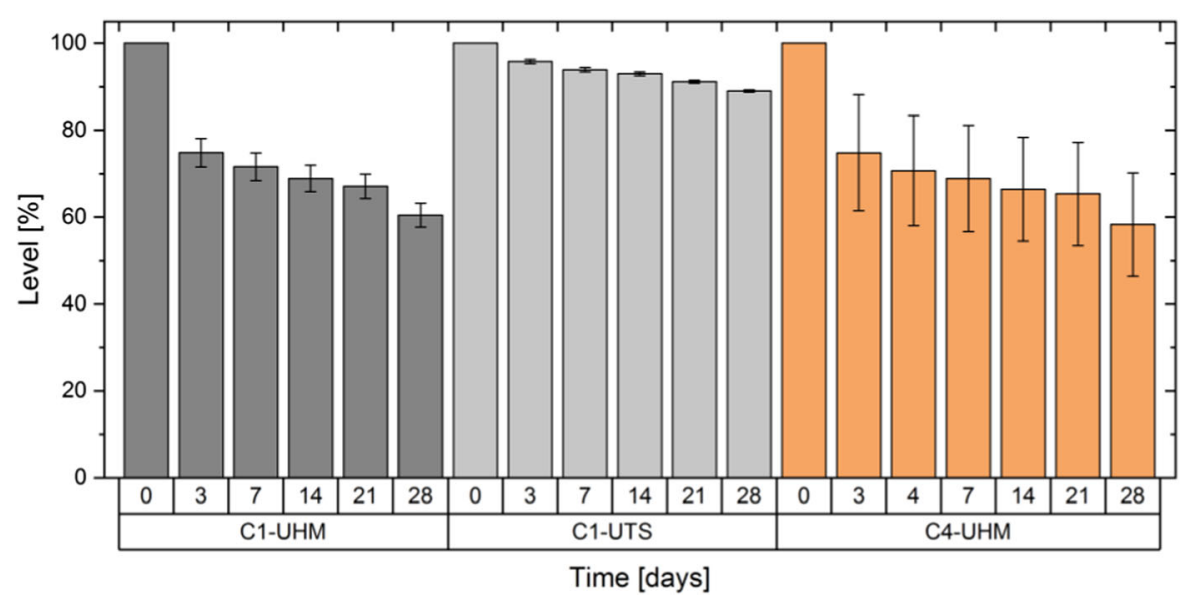

Fig. 4 Prestress level development in the first 28 days after casting. The bars show the average value of the beams investigated and their standard deviations

prestressed concrete elements. For this purpose, three beams of type C1-UHM-CFRP and C4-UHM-CFRP as well as two beams of type C1-UTS-CFRP were tested in 4-point bending tests. Two of the beams with C1-UHM-CFRP tendons and one of the beams for the two other configurations were equipped with an FBGsensors. The remaining beams were stored for long term outdoor tests which were not in the focus of this study.

A similar deflection behaviour was observed in all beam types in the first branch of loading, with nearly constant slope of about $3.40 \mathrm{kN} / \mathrm{mm}$ for all beams. In the second branch, beam types C1-UHM-CFRP and C4-UHM-CFRP showed a load increase rate of
$0.88 \mathrm{kN} / \mathrm{mm}$ and $0.97 \mathrm{kN} / \mathrm{mm}$ respectively. The beam type C1-UTS-CFRP deflected in a softer manner and had a load increase rate of $0.23 \mathrm{kN} / \mathrm{mm}$, see Fig. $6 \mathrm{~A}$. In the transition zone between the first branch and the second branch, the rate of increase of the load decreased progressively. The tendon draw-in was initially measured with the same setup as employed in [36] up to $70 \%$ of the ultimate load but no draw-in could be recorded. The measurement system had to be removed due to safety reasons thereafter. To monitor transfer and bond along the tendon's length the strain measurement by FBG inside the tendons was considered. 


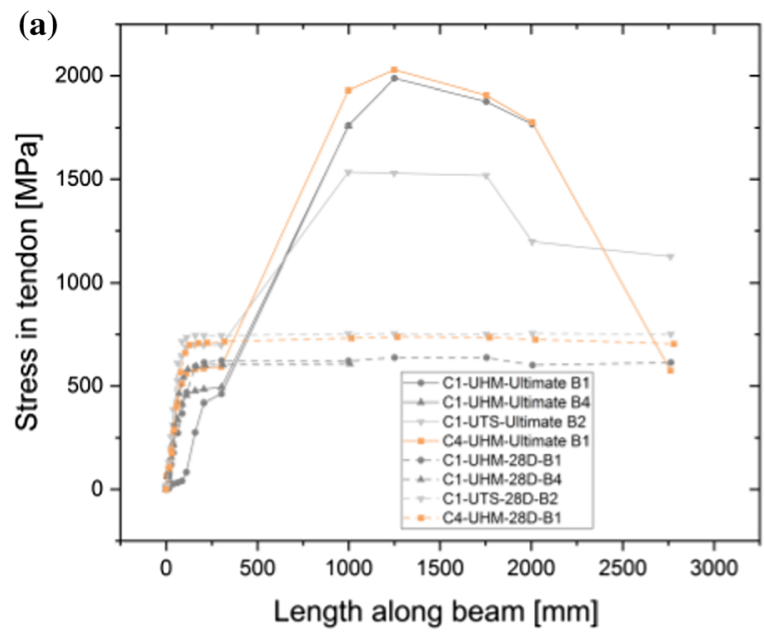

Fig. 5 Stress inside prestressing tendons as measured by the FBG-sensors. Orange indicates the new C4-UHM-CFRP beam type, dark grey the C1-UHM-CFRP beams and light grey the current industry standard C1-UTS-CFRP type. a shows the results 28 days after casting, and at ultimate load during 4-point

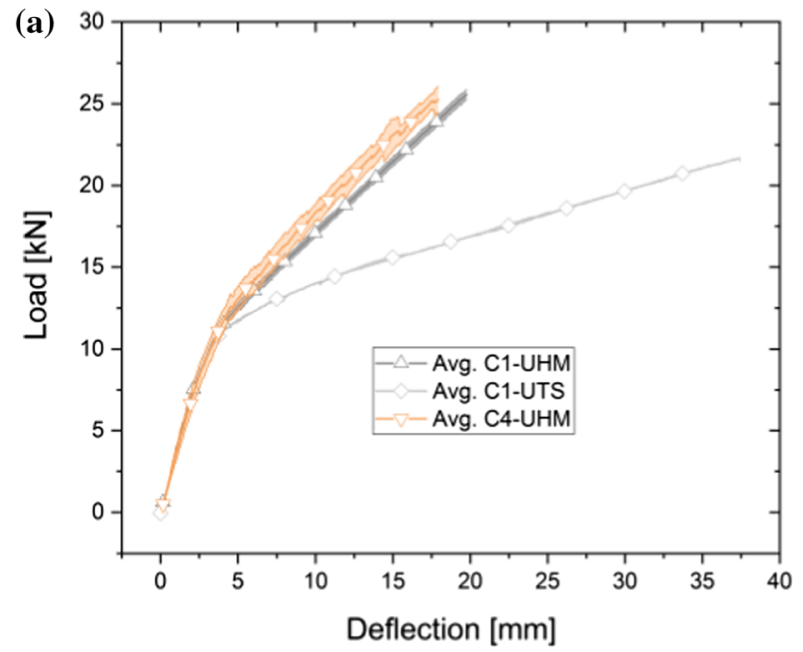

Fig. 6 Results of 4p-bending tests performed, 28 days after casting, on CFRP prestressed beam specimens. Orange indicates the new C4-UHM-CFRP beam type, dark grey the C1-UHMCFRP beams and light grey the current industry standard C1UTS-CFRP type. All beams were initially prestressed to the

All beams failed by a sudden and complete breakdown due to CFRP tendon rupture; at the beams " end faces no tendon slippage could be observed. The averaged maximum failure load is shown for all beam types in Fig. 6 B. The C1-UTS-CFRP beams had clearly the lowest load carrying capacity of $21.68 \mathrm{kN}$. The beams C1-UHM-CFRP and C4-UHM-CFRP reached on average maximum loads of $26.31 \mathrm{kN}$ and

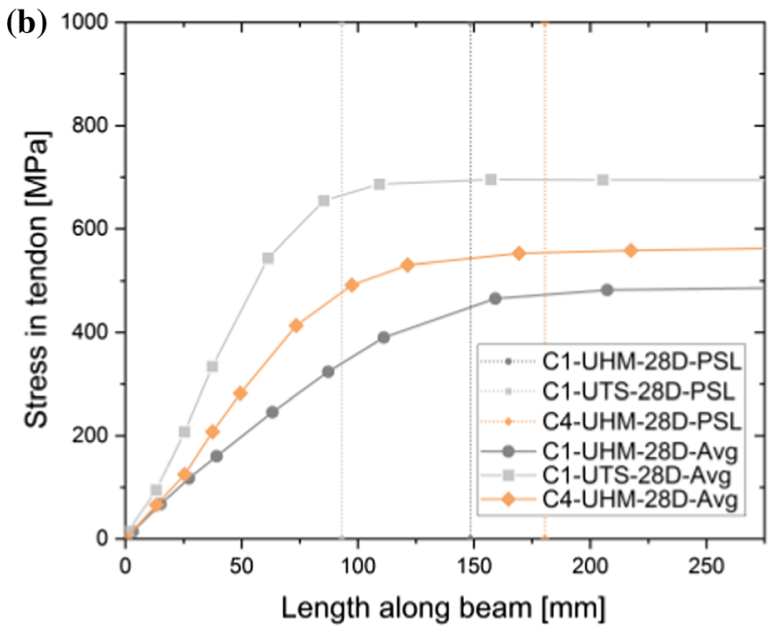

bending tests. b Shows the averaged prestress development in the tendon of the respective beam-tendon combination 28 days after casting, including their transfer length (PSL) as vertical lines

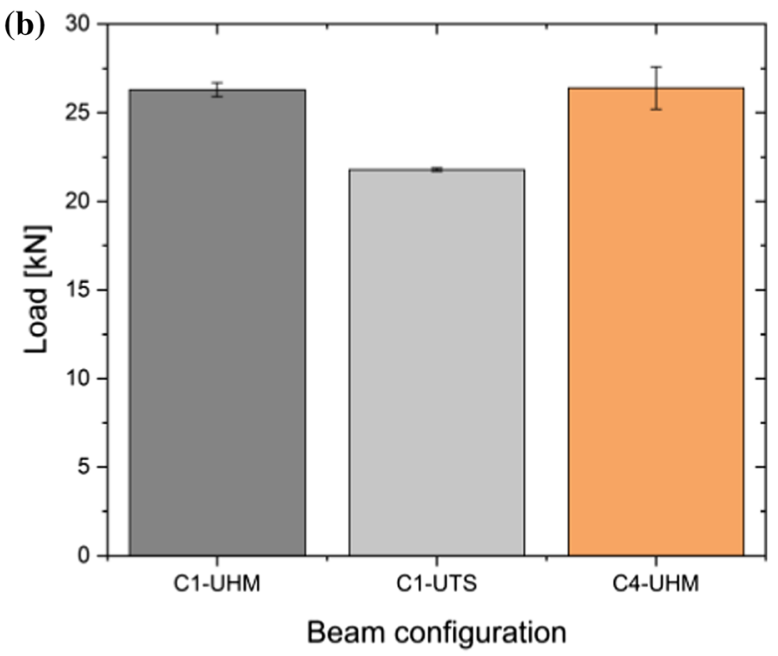

same level of $800 \mathrm{MPa}$. The average bi-linear load deflection behaviour for the different beams is shown in a, together with their standard deviations. The corresponding maximum load bearing capacity is visualized in $\mathbf{b}$, also together with their respective standard deviations

$26.37 \mathrm{kN}$ respectively. The corresponding maximum beam deflections at the middle of the span were measured for C1-UTS-CFRP beams with an average of $37.85 \mathrm{~mm}$. The beams C1-UHM-CFRP and C4UHM-CFRP deflected less and reached an average of $20.76 \mathrm{~mm}$ and $19.18 \mathrm{~mm}$ respectively. At the point of failure, the ultimate strain inside the CFRP prestressing tendons was $1.06 \%$ in the case of UTS-CFRP 
tendons and on average $0.38 \%$ in the case of UHMCFRP tendons. The main results of the 4-point bending tests for each particular beam tested are summarized in Table 5.

Furthermore, the strain distribution on the vertical face of the concrete beams was measured with the DIC system. Typical results for each type of beam are shown in Fig. 7. In this visualization, it is clearly visible that the cracks in the C1-UTS-CFRP beams open more in comparison to both UHM-CFRP prestressed beam types. The beams which are not shown in this graph had very similar strain patterns within their respective group of beams.

\section{Discussion}

\subsection{Effects of UHM-CFRP tendons in prestressed concrete}

The implemented UHM-CFRP tendons were 3.5 times stiffer in comparison to their UTS CFRP counterparts.

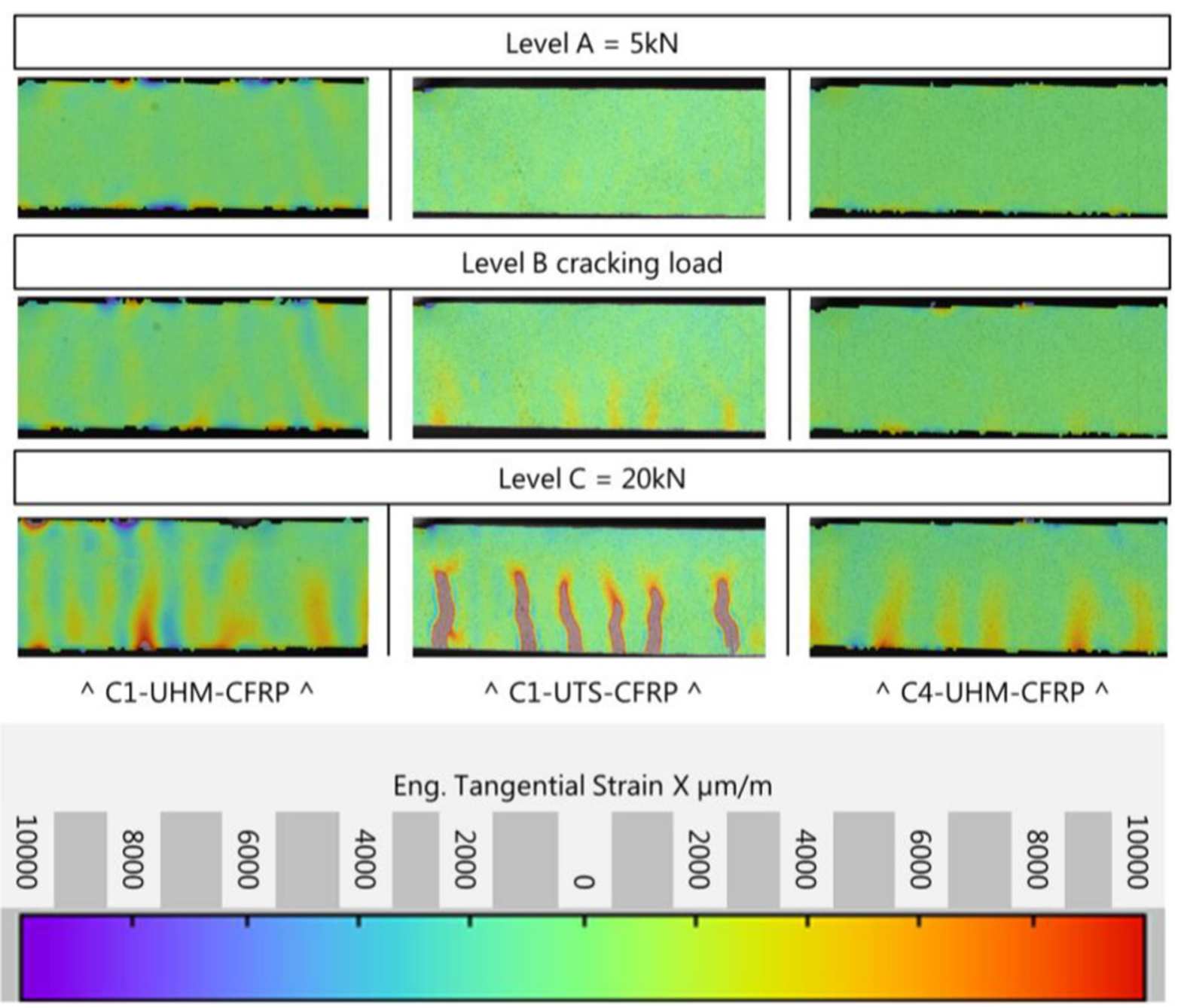

Fig. 7 Visualization of the surface strain pattern along the horizontal direction of the beam's vertical face at selected load levels. Level A corresponds to a load of $5 \mathrm{kN}$, level B to the cracking load and level $\mathrm{C}$ to $20 \mathrm{kN}$. The left column represents a beam of type C1-UHM-CFRP, the middle column an industry standard type C1-UTS-CFRP and the right column the new C4-
UHM-CFRP beam type. The distance between the cracks in the pattern of the different beam types was similar; all showed about 6 cracks in the same field of view. The crack width was visually larger for beams prestressed with C1-UTS CFRP tendons. A detailed crack width analysis was not performed 
Not surprisingly, their response to the beam's strain changes, due to shrinkage and creep after the prestress release, were found to be more significant and resulted in much lower tendon stress levels. In addition, the measurement of the prestress transfer length and the prestress level revealed a large scatter for beams prestressed with UHM-CFRP tendons; see results in Figs. 3 and 4. Both of these values are generally dependent on the effective strain distributions inside the beams that are reached after prestress release (when elastic shortening of the concrete happens) but also over time (due to creep and shrinkage of the concrete). In this context, local concrete material variations, geometrical beam imperfections and prestress tendon positioning tolerances seem likely to affect the prestress-related parameters in UHM-CFRP prestressed beams more significantly than in UTSCFRP prestressed beams. Due to the higher longitudinal stiffness of UHM-CFRP, this effect is proposed to be resulting in the larger scatter found in the experiments. In other words, beams prestressed with UHM-CFRP can be expected to be more sensitive in their resulting prestress force and this uncertainty should be considered when designing such beams in practice.

\subsection{Effects of UHM-CFRP tendons}

on the structural behaviour of prestressed concrete beam elements

In 4-point bending, the scatter in the load-deflection behaviour was found to be much smaller within each group of beams if compared to the analysis of the prestress level and length. In the case of deflection, the overall beam geometry was dominant for the investigated behaviour. Within the given beam dimensions, the influence of the local material variations, the geometrical imperfections and the tendon positioning tolerances were of minor importance and likely to have resulted in only small deviations within each respective group of beams.

The tested prestressed concrete beams showed the expected bi-linear load deflection behaviour; see [43, 44] and Fig. 6a. This bi-linear behaviour could be described by the flexural stiffness in the respective section. The flexural stiffness follows the gross moment of inertia $\left(\mathrm{I}_{\mathrm{g}}\right)$ in the first branch $\left(\mathrm{M}<\mathrm{M}_{\mathrm{cr}}\right)$, the cracked moment of inertia $\left(\mathrm{I}_{\mathrm{cr}}\right)$ in the second branch $\left(\mathrm{M}>\mathrm{M}_{\mathrm{cr}}\right)$ always in combination with the elastic modulus (E) of the concrete [43]. For the beams used in this study, $I_{g}$ is affected little by the presence of the CFRP tendons, see Table 3. Consequently, the behaviour until cracking should be comparable for all investigated beam configurations, which was indeed confirmed by the experimental results. When using the transformed area diagram to calculate $\mathrm{I}_{\mathrm{cr}}$, see [45], it is obvious that $\mathrm{I}_{\mathrm{cr}}$ must be smaller than $\mathrm{I}_{\mathrm{g}}$. In this case the contribution of the rectangular cross section of the concrete beam decreases while the contribution of the CFRP tendons, due to Steiner's theorem, increases. Moreover, the contribution of the CFRP tendons to $\mathrm{I}_{\mathrm{cr}}$ is proportional to the modular ratio between tendon and concrete $\left(n=E_{c f r p} / E_{c}\right)$, which would logically result in a stiffer deflection behaviour in the cracked state for UHM-CFRP tendons in comparison to their UTS-CFRP counterparts. Both expectations were confirmed by the experimental results. In fact, the relation between the cracked moments of inertia $\mathrm{I}_{\text {cr_UHM }} / \mathrm{I}_{\text {cr_UTS }}$ was calculated to be 2.9 , which corresponds well to the ratio of 3.0 found in the experimental deflection of both beam types.

However, the load bearing capacity of beams prestressed by UHM-CFRP tendons exceeded the capacity of beams prestressed by UTS-CFRP tendons in the experiments. This was unexpected, considering the results of the tensile tests on the respective materials (see Table 4). Based on these results, in combination with the analytical beam deflection model of Rezazadeh et al. [33], the maximum load carrying capacity of UTS-CFRP prestressed beams was calculated to be $11.34 \mathrm{kNm}$ and for UHM-CFRP beams $11.10 \mathrm{kNm}$. Both calculations assume a tendon tensile failure. This could be assumed based on calculating a critical amount of CFRP. A value smaller than the critical value would yield towards a tendon's tensile failure and a value larger to concrete crushing. For the investigated beams, following [33], the critical amount of CFRP was calculated to be $2.01 \%$ for $\mathrm{C} 1$ UHM-CFRP prestressed beams and $0.61 \%$ for $\mathrm{C} 1$ UTS-CFRP prestressed beams. The actual amount of CFRP in the tested beams reached only $0.36 \%$. Accordingly, the assumption in the model to have tendon tensile failure in both cases was verified.

The employed model by Rezazadeh et al. described the experimental load-deflection behaviour with accuracy (see Fig. 8a). The observed differences in the load bearing capacity could be based on multiple reasons. Two of them are discussed in the following. 
Table 3 Moments of inertia of cracked and un-cracked beams and the modular ratio between CFRP and concrete

\begin{tabular}{lllll}
\hline Beam configuration & $I_{\mathrm{g}}\left(\mathrm{mm}^{4}\right)$ & $I_{\text {cr_exp }}\left(\mathrm{mm}^{4}\right)$ & $I_{\text {cr_cal }}\left(\mathrm{mm}^{4}\right)$ & $n(-)$ \\
\hline C1-UTS-CFRP & $2.97 \times 10^{7}$ & $2.59 \times 10^{6}$ & $2.65 \times 10^{6}$ & 4 \\
C1-UHM-CFRP & $3.11 \times 10^{7}$ & $7.75 \times 10^{6}$ & $7.66 \times 10^{6}$ & 14 \\
C4-UHM-CFRP & $3.08 \times 10^{7}$ & n.a & n.a & 12 \\
\hline
\end{tabular}

n.a. means not available

n (-) means modular ratio between CFRP and concrete

Table 4 Longitudinal properties of CFRP tendons

\begin{tabular}{llllllr}
\hline Tendon material & $\begin{array}{l}\text { Tensile Strength } \\
\mathrm{S}_{11 \mathrm{u}} \\
(\mathrm{MPa})\end{array}$ & $\mathrm{SD}$ & $\begin{array}{l}\text { Young's Modulus E } \\
(\mathrm{GPa})\end{array}$ & SD & $\begin{array}{l}\text { Design Tensile } \\
\text { Strength } \mathrm{S}_{11 \mathrm{uD}} \\
(\mathrm{MPa})\end{array}$ & $\begin{array}{l}\text { Ultimate tendon stress } \\
\text { in beams } \mathrm{S}_{11 \mathrm{u} \_ \text {beams }} \\
(\mathrm{MPa})\end{array}$ \\
\hline UHM-CFRP & 1562 & 68 & $509^{*}$ & $22^{*}$ & $1426^{*}$ & 1924 \\
UTS-CFRP & 2031 & 31 & 145 & 4 & 1969 & 1561 \\
\hline
\end{tabular}

*data equivalent to [3]

First, the concrete properties themselves could be affected and hence the critical ratio between the CFRP tendons and the concrete could have been changed and so the failure mode of the beams. The beam's top-fibre compressive strain during loading was analysed after the 4 point bending experiments with the help of the DIC system, Fig. $8 \mathrm{~b}$. These results indicate clearly that the maximum compressive strain in UTS-prestressed beams reached a value of 0.0018 and in UHM-

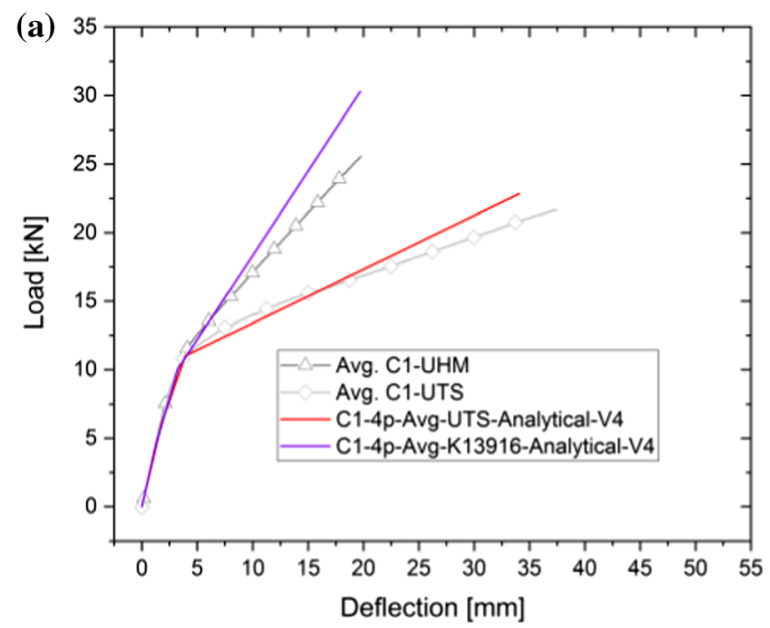

Fig. 8 Influences on a prestressed beam's deflection behavior: a Analytical deflection modelling, based on the approach of Rezazadeh et al. [33], in comparison to the experimental results. prestressed beams 0.0012 respectively. Both values are significantly lower than the suggested theoretical failure strain of 0.003 given by ACI [44] and a experimentally tested compressive strains in [46]. Hence it could be concluded that the concrete was far from crushing and is not expected to be the cause of the beam's early failure.

Secondly, the stress distribution inside the CFRP tendons in a cracked section of the beam could be

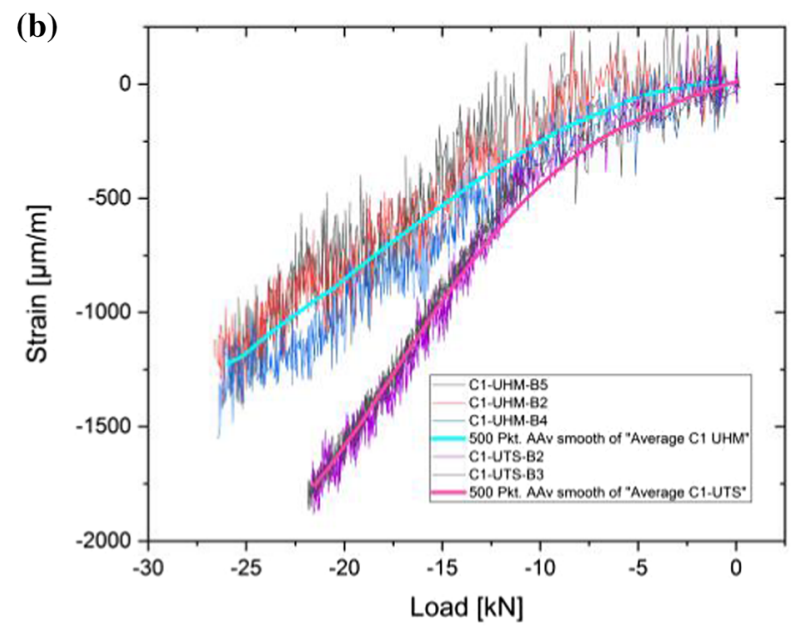

b Development of the concrete's top fibre strain for C1-UHMCFRP beams and C1-UTS-CFRP-beams during loading 
different to the assumed ideal tensile stress condition. This case would be reasonable if large transverse stresses were introduced either by the large deflections of the UTS-CFRP prestressed beams or due to the different CFRP material properties. Hence, the tendon could show an unexpected early failure.

To shed light on the stress distribution in the CFRP tendons, the investigated beams were analysed by a simplified finite element analysis (FEA) in Abaqus 6.14 using a quarter model of a beam's cut-out section with a length of $60 \mathrm{~mm}$, a height of $157.5 \mathrm{~mm}$ and a width of $45 \mathrm{~mm}$. In this model, all materials exhibited linear elastic behaviour. The CFRP materials were defined by TYPE $=$ ENGINEERING CONSTANTS to consider their anisotropic properties and the concrete was simply represented by the material TYPE = ISOTROPIC. The respective properties were taken from Tables 1, 4 and [6]. Concrete and CFRP tendons were modelled with elements of TYPE = C3D20R. The beam's concrete geometry was cut to represent the crack until the position of the neutral axis as observed in the experiments. The uncracked area in the top section of the beam and the related cross section of the tendon were restricted by the BOUNDARY CONDITION of TYPE $=$ ZSYMM, where Z-direction being the normal direction of the ideal crack surface. The global mesh size was $3.7 \mathrm{~mm}$ and the refined mesh around the crack area was $0.5 \mathrm{~mm}$. For the LOAD CONDITION, at first the cracked cutout section was prestressed by a PREDEFINED FIELD of TYPE = STRESS to the same level as found in the experiments. Afterwards the model was continuously loaded with the bending moment corresponding to the experimentally found ultimate load bearing capacity for the respective beam type, see Fig. 6 and Table 5. To account for a possible damage of the bond interface between tendon and concrete, the first $3 \mathrm{~mm}$ from the crack towards the tendon were modelled with a SURFACE TO SURFACE CONTACT using a high tangential friction $(\mu=0.8)$ of TYPE $=$ PENALTY and a HARD CONTACT in the normal direction. The remaining contact of the tendon was ideally bonded by using TIE to the surrounding concrete. Time-dependent properties of the concrete, such as creep and shrinkage, were not included in the model. This simplification was justified by the short time frame of the investigated cracked beam situation, shortly before failure. For validation of the model, the curvature at the ultimate bending moment as well as the prestress inside the tendon after the prestress release was analysed and found to be in good agreement with the experiments.

At the experimental failure load, the UTS-CFRP prestressed beams showed a tensile stress in the tendon's vertical direction (S22) of $>50 \mathrm{MPa}$ and the UHM-CFRP tendons of around 20-25 MPa, Fig. 9. Both are critical values in the transverse direction, e.g. in [47] a comparable unidirectional UTS-CFRP material reached a transverse tensile strength of only $24 \mathrm{MPa}$. It can be concluded that the low load bearing capacity of the UTS-CFRP beams was likely due to the unfavourable stress situation in the limit state. According to the FEA, this was found to be more critical for the UTS-CFRP beam than for the UHMCFRP beam, see Fig. 9.

\subsection{Effects of LCHPC on CFRP prestressed structural elements}

The tested LCHPC recipe (C4) had both Young's modulus and compressive strength very close to the current industry standard C1, see Table 1. Hence, the deflection behaviour was mainly controlled by the UHM CFRP prestressing tendons and not by the LCHPC, see Fig. 6-A. In addition, effects on the prestress loss based on the lower shrinkage and creep of LCHPC (C4) in comparison to HPC (C1) were expected, see [6], but could not be identified in the experimentally investigated prestressed concrete beams. This was mostly caused by the high scatter in the experimental results observed in the C4-UHMCFRP beam specimens, see Fig. 4.

Recently, in [6], the effects of shrinkage, creep and elastic shortening on prestress losses in LCHPC prestressed elements were estimated based on an idealized and simplified FEA. The geometry of the studied elements was based on a shrinkage and creep test specimen to reduce geometrical effects of the specimen on modelling shrinkage and creep and hence to allow a comparison between modelling and the respective experiments. The beams used in this study did not have the same dimensions as the specimens examined in [6]. The cross-sectional area of the employed beams was about 2 times larger and they were about 8 times longer than the creep and shrinkage specimens in [6]. In a first step, the Abaqus 6.14 FEA model, developed in [6], was adapted in geometry and applied to the beam specimens tested in this study. The 
Table 5 Summarized results of beam tests

\begin{tabular}{|c|c|c|c|c|c|c|c|c|c|}
\hline $\begin{array}{l}\text { Beam } \\
\text { configuration }\end{array}$ & $\begin{array}{l}\text { Cracking } \\
\text { load }(\mathrm{kN})\end{array}$ & $\begin{array}{l}\text { Midspan } \\
\text { deflection } \\
\text { cracking } d_{\mathrm{c}} \\
(\mathrm{mm})\end{array}$ & $\begin{array}{l}\text { Stiffness } \\
\text { unracked } \\
(\mathrm{kN} / \mathrm{mm})\end{array}$ & $\begin{array}{l}\text { Ultimate } \\
\text { load }(\mathrm{kN})\end{array}$ & $\begin{array}{l}\text { Ultimate } \\
\text { midspan } \\
\text { deflection } d_{\mathrm{u}} \\
(\mathrm{mm})\end{array}$ & $\begin{array}{l}\text { Ultimate } \\
\text { tendon } \\
\text { strain }(\%)\end{array}$ & $\begin{array}{l}\text { Stiffness } \\
\text { cracked } \\
(\mathrm{kN} / \mathrm{mm})\end{array}$ & $\begin{array}{l}\text { Failure } \\
\text { mode } \\
(-)\end{array}$ & $\begin{array}{l}d_{\mathrm{u}} / \\
d_{\mathrm{c}} \\
(-)\end{array}$ \\
\hline C1-UTS B1 & 12.43 & 6.37 & 1.95 & 21.65 & 37.42 & 1.06 & 0.30 & $\mathrm{TF}$ & 5.87 \\
\hline C1-UTS B2 & 12.29 & 5.99 & 2.05 & 21.85 & 38.28 & n.a & 0.30 & TF & 6.39 \\
\hline C1-UHM B1 & 10.76 & 3.56 & 3.02 & 26.59 & 21.44 & 0.39 & 0.89 & $\mathrm{TF}$ & 6.02 \\
\hline C1-UHM B2 & 11.13 & 3.63 & 3.07 & 26.42 & 20.79 & 0.35 & 0.89 & TF & 5.73 \\
\hline C1-UHM B3 & 11.16 & 3.56 & 3.13 & 25.91 & 19.58 & n.a & 0.92 & $\mathrm{TF}$ & 5.50 \\
\hline C4-UHM B1 & 11.84 & 3.81 & 3.11 & 27.68 & 20.64 & 0.40 & 0.94 & TF & 5.42 \\
\hline C4-UHM B2 & 11.66 & 2.87 & 4.06 & 25.98 & 16.88 & n.a & 1.02 & $\mathrm{TF}$ & 5.88 \\
\hline C4-UHM B3 & 9.04 & 3.20 & 2.83 & 25.43 & 18.91 & n.a & 1.04 & $\mathrm{TF}$ & 5.91 \\
\hline
\end{tabular}

TF means tendon failure

n.a. means not available

(a)

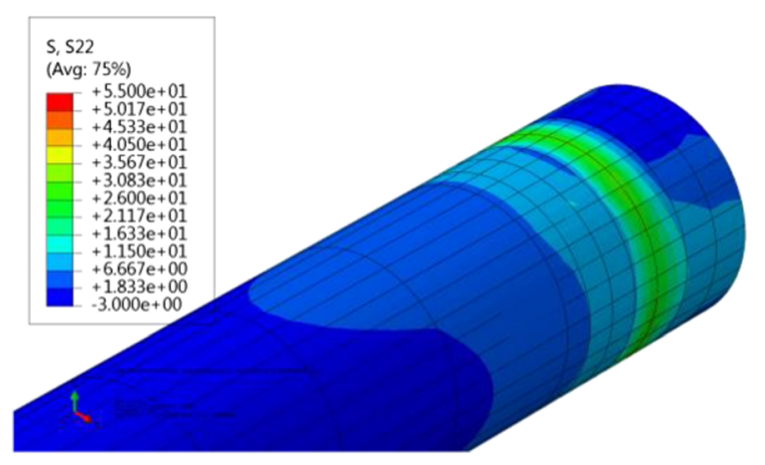

(b)

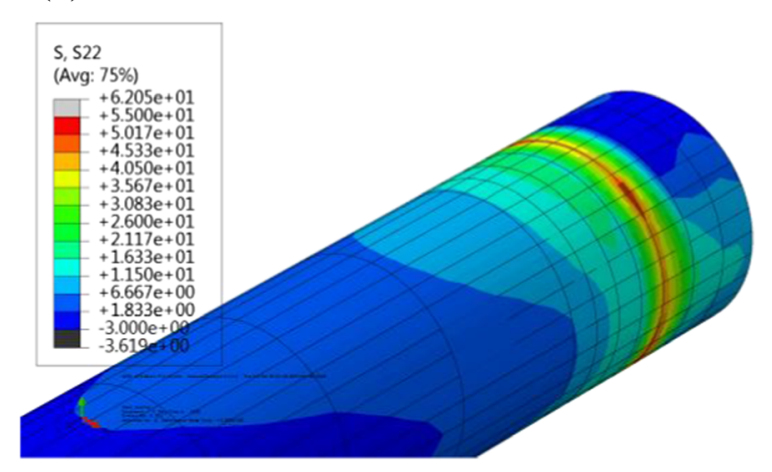

Fig. 9 FEA results showing the vertical stress component (S22) in the CFRP tendons at ultimate load condition. a For a C1-UHMCFRP beam. b For a C1-UTS-CFRP prestressed beam

initial prestress of $800 \mathrm{MPa}$ was applied to the tendons with a PREDEFINED FIELD of TYPE = STRESS, shrinkage of concrete was modelled by a thermal expansion coefficient analogy and creep by the function *VISCOELSTIC. Further details about the FEA can be found in [6]. Prestress losses in the FEA were determined by comparing the remaining prestress in the tendons at a certain time with the initial prestress applied to the tendons. For validation, the results of prestress losses after 28 days were compared to the measured prestress losses, see Fig. 10a. The contribution of the elastic shortening, shrinkage and creep on the prestress loss were analysed based on the FEA, Fig. 10b. As in [6], it was found that all three contributors deliver noteworthy amounts of prestress loss to the investigated beam specimens. Based on the
FEA, the prestress loss in LCHPC beams was calculated to be only around $3 \%$ less in comparison to their HPC beam counterparts, see Fig. 10a and b. Considering the large scatter in the experimental prestress loss measurements, in particular for C4-UHM-CFRP beams with results based on only two beams, this effect could neither be disproved nor confirmed by the experiments.

As a result, the theoretical benefit of a higher remaining prestress in the structure due to the lower creep and shrinkage was not significant, not even in the case when the tensile-wise very sensitive UHMCFRP tendons were used for prestressing. However, the experiments described in this paper confirm that the LCHPC, with their clinker reduction of up to $70 \%$, could be used as a replacement for the current HPC in 

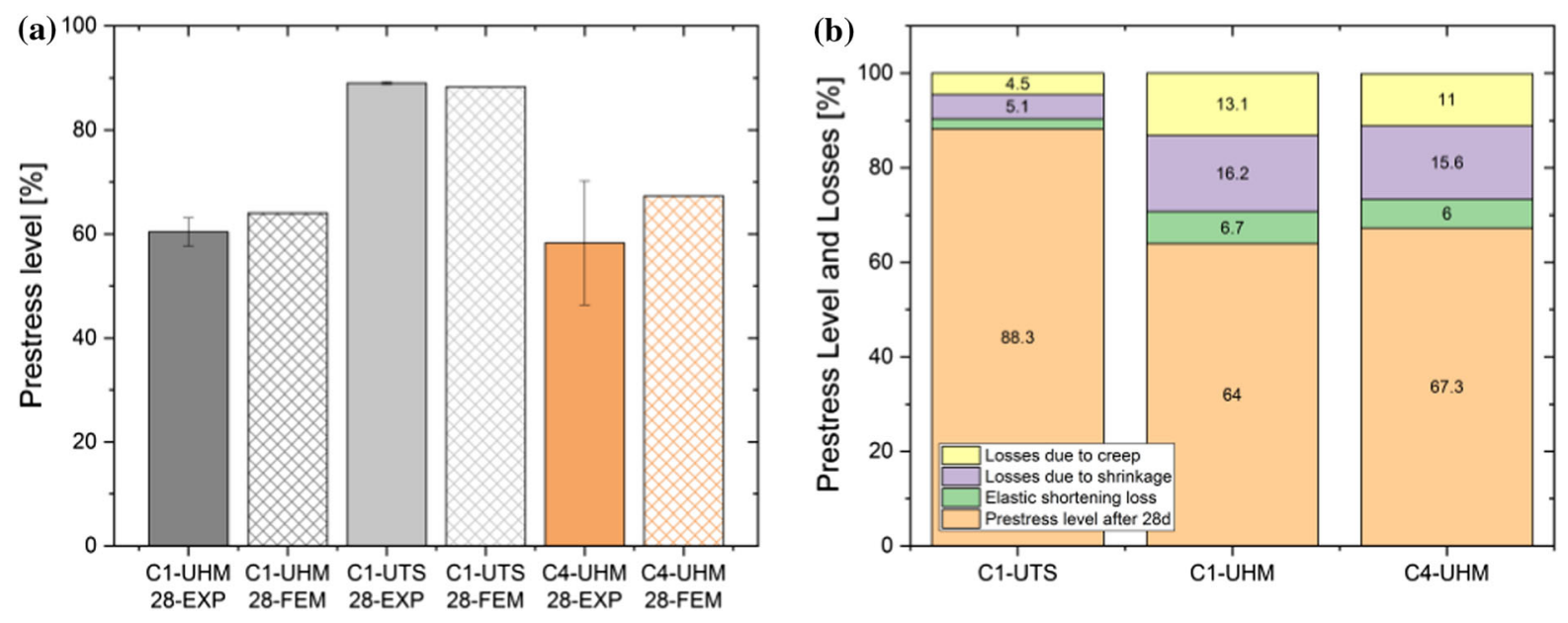

Fig. 10 Prestress loss assessment. a Comparison of experimental results with FEA predictions. b Breakdown of prestress losses into the three main contributions of shrinkage, creep and elastic shortening based on the FEA

CFRP prestressed structural elements without compromising their short term mechanical performance. These results are considered to be valid for the specific case investigated in this study. The effects of creep and shrinkage might be different in structures of other dimensions, which would need further investigations that are beyond the scope of this work.

\section{Conclusions}

Based on monitoring the prestress inside beam specimens up to 28 days after casting, full scale 4-point bending beam tests and additional upscaling of a small scale FEA model to structural level in Abaqus 6.14, the following conclusions can be drawn:

- The prestress transfer length is affected by tendon stiffness. Here, the shear stress transfer between the prestressing tendon and the concrete is dependent mainly on the stiffness of the materials in the direction of the applied prestress. Hence, in the same concrete matrix, the stiffer tendon has the longer transfer length.

- Beams prestressed with stiffer tendons experience larger prestress losses. Elastic shortening, shrinkage and creep all contribute to a shortening of the concrete beam in the prestress direction. A stiffer prestressing tendon, embedded and bonded to the concrete, will always experience more prestress loss due to the same amount of shortening.
- In the cracked state UHM-CFRP prestressed beams showed less deflection, narrower cracks and an increased load bearing capacity in comparison to their UTS-CFRP prestressed opponents. When using UHM-CFRP, the beams could be used more efficiently in terms of their structural performance.

- LCHPC, with much lower clinker content than traditional HPC, is equally suited for CFRPprestressing applications. In particular, the flexural behaviour of prestressed beams was found to be equivalent to that of the reference HPC.

The results of this work show very good potential for improving the current CFRP prestressing technology at the structural level by using UHM tendons. While LCHPC has lower creep and shrinkage, in the particular structure investigated in this study no benefits in term of reducing prestress losses was observed, possibly due to the high scatter of these measurements. However, these results still focus mainly on the short-term behaviour of a prestressed beam. Critically, also data about the structural behaviour and its integrity over a longer period of time (several years) in harsh environmental conditions would be needed. This would possibly help industrial stakeholders to gain confidence in these new materials and finally bring this technology into construction practice.

Acknowledgements This research project was part of the joint project "Low energy concrete" within the framework of 
the National Research Programme "Energy Turnaround “ (NRP 70) of the Swiss National Science Foundation (SNSF). Further information on the National Research Programme can be found at http://www.nrp70.ch/en/projects/building-settlement/lowenergy-concrete. We are grateful to Daniel Käppeli, Sebastiano Valvo, Marcel Käppeli, and Daniel Völki for their strong support during sample production and testing.

Funding Open Access funding provided by Lib4RI - Library for the Research Institutes within the ETH Domain: Eawag, Empa, PSI \& WSL.

Open Access This article is licensed under a Creative Commons Attribution 4.0 International License, which permits use, sharing, adaptation, distribution and reproduction in any medium or format, as long as you give appropriate credit to the original author(s) and the source, provide a link to the Creative Commons licence, and indicate if changes were made. The images or other third party material in this article are included in the article's Creative Commons licence, unless indicated otherwise in a credit line to the material. If material is not included in the article's Creative Commons licence and your intended use is not permitted by statutory regulation or exceeds the permitted use, you will need to obtain permission directly from the copyright holder. To view a copy of this licence, visit http://creativecommons.org/licenses/by/4.0/.

\section{References}

1. Terrasi G, Battig G, Bronnimann R (2002) Pylons made of high-strength spun concrete and prestressed with carbon fibre reinforced plastic for high power transmission lines. Int J Mater Prod Technol 17(1):32-45

2. Terrasi GP (1998) Mit Kohlenstoffasern vorgespannte Schleuderbetonrohre, Diss. Techn. Wiss. ETH Zürich, Nr. 12454, Ref.: H. Bachmann; Korref.: U. Meier

3. Terrasi G, McIntyre E, Bisby L, Lämmlein T, Lura P (2016) Transient Thermal Tensile Behaviour of Novel Pitch-Based Ultra-High Modulus CFRP Tendons. Polymers 8(12):446

4. EN 197-1 (2011) Cement-Part 1: Composition, Specifications and Conformity Criteria for Common Cements, European Committee for Standarization (CEN), Brussels, 2011.

5. SIA 2052:2016 (2016) Ultra-high performance fiber reinforced concrete (UHPFRC) - Materials, design and execution, Schweizerischer Ingenieur und Architektenverein (SIA), Zürich

6. Lämmlein TD, Messina F, Wyrzykowski M, Terrasi GP, Lura P (2019) Low clinker high performance concretes and their potential in CFRP-prestressed structural elements. Cement Concr Compos 100:130-138

7. Dinges T (2009) The history of prestressed concrete: 1888 to 1963. Kansas State University, Manhatten

8. Nanni A (1993) FRP reinforcement for prestressed and nonprestressed concrete structures, Developments in civil engineering No. 42: Fiber-Reinforced-Plastic (FRP) Reinforcement for Concrete Structures, Elsevier
9. Stoll F, Saliba JE, Casper LE (2000) Experimental study of CFRP-prestressed high-strength concrete bridge beams. Compos Struct 49(2):191-200

10. Micelli F, Nanni A (2004) Durability of FRP rods for concrete structures. Constr Build Mater 18(7):491-503

11. Hoshijima T, Yagi K, Tanaka T, Ando T (1996) Properties of CFRP composites for concrete structures. In: First International Conference on Composites in Infrastructure, Tucson, Arizona, USA, pp 227-241

12. Magnel G (1954) Prestressed concrete. McGraw-Hill, New York

13. Tadros MK, Al-Omaishi N, Seguirant SJ, Gallt JG (2003) Prestress losses in pretensioned high-strength concrete bridge girders, NCHRP Report No. 496, Transportation Research Board, Washington, DC, United States.

14. Tadros MK, Ghali A, Meyer AW (1985) Prestressed loss and deflection of precast concrete members. PCI J 30(1):114-141

15. Zia P, Preston HK, Scott NL, Workman EB (1979) Estimating prestress losses. ConcrInt 1(6):32-38

16. Preston HK, Barker JM, Boecker HC Jr, Dull R, Edwards HH, Huang T, Iragorri J, Koretzky HP, Kraemer PE, Magura DD (1975) Recommendations for estimating prestress losses. PCI J 20(4):44-75

17. Maaskant R, Alavie T, Measures R, Tadros G, Rizkalla S, Guha-Thakurta A (1997) Fiber-optic Bragg grating sensors for bridge monitoring. Cement Concr Compos 19(1):21-33

18. Caro LA, Martí-Vargas JR, Serna P (2013) Prestress losses evaluation in prestressed concrete prismatic specimens. EngStruct 48:704-715

19. Terrasi GP, Wyrzykowski MR, Lura P (2016) Self-prestressed reinforced concrete elements, Patent No. EP3106446A1

20. Kim ST, Park Y, Park SY, Cho K, Cho JR (2015) A sensortype PC strand with an embedded FBG sensor for monitoring prestress forces. Sensors 15(1):1060-1070

21. Bruggeling ASG (1999) Controlling transmission of prestress by bond in progress Düsseldorf. VBT VerlagBau + Technik, Düsseldorf

22. Nanni A, Utsunomiya T, Yonekura H, Tanigaki M (1992) Transmission of prestressing force to concrete by bonded fiber reinforced plastic tendons. ACI Struct J 89(3):335-344

23. Taerwe L, Pallemans I (1995) Force transfer of AFRP bars in concrete prisms. In: Non-metallic (FRP) reinforcement for concrete structures: proceedings of the second international RILEM symposium (FRPRCS-2), Ghent, pp 154-163

24. Gilstrap JM, Burke CR, Dowden DM, Dolan CW (1997) Development of FRP reinforcement guidelines for prestressed concrete structures. J Compos Constr 1(4):131-139

25. Bakis C, Bank L, Brown V, Cosenza E, Davalos J, Lesko J, Machida A, Rizkalla S, Triantafillou T (2002) Fiber-reinforced polymer composites for construction-state-of-theart review. J Compos Constr 6(2):73-87

26. Burgoyne C (1997) Rational use of advanced composites in concrete. In: Proceedings of the 3rd international symposium on non-metallic (FRP) reinforcement for concrete structures, Japan Concrete Institute, pp 75-88

27. Terrasi GP (2013) Prefabricated thin-walled structural elements made from high performance concrete prestressed with CFRP wires. J Mater Sci Res 2(1):1 
28. Terrasi GP, Meier U, Affolter C (2014) Long-term bending creep behavior of thin-walled CFRP tendon pretensioned spun concrete poles. Polymers 6(7):2065-2081

29. Terrasi GP, Lees JM (2003) CFRP prestressed concrete lighting columns. ACI Special Publ 215:55-74

30. Dolan CW (2001) Flexural design of prestressed concrete beams using FRP tendons. PrestressedConcrInst J 46(2):76-87

31. Lou T, Lopes SMR, Lopes AV (2016) Time-dependent behavior of concrete beams prestressed with bonded AFRP tendons. Compos B Eng 97:1-8

32. Bodzak P (2019) Prestressing and preloading effect in RC slabs strengthened with normal and pretensioned CFRP EBR strips. Compos B Eng 169:19-28

33. Rezazadeh M, Barros J, Costa I (2015) Analytical approach for the flexural analysis of RC beams strengthened with prestressed CFRP. Compos B Eng 73:16-34

34. Fam AZ, Rizkalla SH, Tadros G (1997) Behavior of CFRP for prestressing and shear reinforcements of concrete highway bridges. ACI Struct J 94(1):77-86

35. ACI440.2R-17 (2017) Guide for the Design and Construction of Externally Bonded FRP Systems for Strengthening Concrete Structures, Farmington Hills (MI): American Concrete Institute

36. Lämmlein T, Messina F, Griffa M, Terrasi G, Lura P (2017) Bond performance of sand coated UHM CFRP Tendons in high performance concrete. Polymers 9(2):78

37. Terrasi GP, Meier U (2014) Long term bending creep behaviour of thin walled CFRP pretensioned high strength spun concrete poles under sustained load. In: El-Hacha R (ed) Proceedings of the 7th international conference on FRP composites in civil engineering, International Institute for FRP in Construction, Vancouver, Canada

38. Nanni A, Tanigaki M (1992) Pretensionedprestressed concrete members with bonded fiber reinforced plastic tendons: development and flexural bond lengths (static). ACI Struct J 89(4):433-441

39. Terrasi GP, Bisby L, Barbezat M, Affolter C, Hugi E (2012) Fire behavior of thin CFRP pretensioned high-strength concrete slabs. J Compos Constr 16(4):381-394

40. Rao Y-J (1998) Fiber Bragg grating sensors: principles and applications. In: Grattan KTV, Meggitt BT (eds) Optical Fiber Sensor Technology Optoelectronics, Imaging and Sensing, vol 2. Springer, Boston, MA, United States, pp 355-379

41. Grattan KTV, Sun T (2000) Fiber optic sensor technology: an overview. Sens Actuators A 82(1):40-61

42. Russell BW, Burns NH (1997) Measurement of transfer lengths on pretensioned concrete elements. J StructEng 123(5):541-549

43. Gar SP, Mander JB, Hurlebaus S (2018) Deflection of FRP Prestressed Concrete Beams. J Compos Constr 22(2):04017049

44. ACI440.3R-04 (2004) Guide test methods for fiber-reinforced polymers (FRPs) for reinforcing or strengthening concrete structures. Farmington Hills (MI): American Concrete Institute

45. Faruqi M, Khan MS (2019) Deflection behavior of a prestressed concrete beam reinforced with carbon fibers at elevated temperatures. Frontiers StructCivEng 13(1):81-91

46. Hampel T, Speck K, Scheerer S, Ritter R, Curbach M (2009) High-performance concrete under biaxial and triaxial loads. J EngMech 135(11):1274-1280

47. Wang S-X, Wu L-Z, Ma L (2010) Low-velocity impact and residual tensile strength analysis to carbon fiber composite laminates. Mater Des 31(1):118-125

Publisher's Note Springer Nature remains neutral with regard to jurisdictional claims in published maps and institutional affiliations. 